\title{
Analisis Teknik Permainan Gitar Pada Komposisi Gitar "Sunburst” Karya Andrew York
}

\author{
Fikra Zaky Aryamani Salman \\ Progam Studi Musik Fakultas Bahasa dan Seni Unversitas Negeri Surabaya \\ email: fzme350@gmail.com
}

\begin{abstract}
One of the composers of the 19th century was Andrew York, born in 1958 in Atlanta and raised in Virginia and a love of music instilled at an early age. Of the many compositions made by Andrew York, sunburst is one composition that is very popular among the people. Sunburst itself was written in 1986 and published in 1998. This research aims to; 1) Describe guitar playing techniques in the composition of sunburst by Andrew York; 2) Describe the supporting factors of classical guitar techniques in playing the composition of Andrew York's sunburst. Research is focused on classical guitar playing techniques contained in Andrew York's sunburst. This research is a qualitative descriptive study. Data collection is done by participatory observation, documentation, and reference. The research subject in this study was Andrew York's sunburst scores, while the object of his research was the guitar playing technique in the composition of sunburst by Andrew York. The data analysis technique was carried out qualitatively which consisted of data reduction, data display, verification. Data validation is obtained by triangulation of data and observer triangulation. The results showed that 1) Guitar playing techniques used in Andrew York's sunburst included; Slur, Barre, Harmonic, Glissando, and Tirando's Quotations, 2) The obstacle factors that need to be considered in playing Andrew York's sunburst are related to classical guitar playing techniques, namely; speed, power, health and physical endurance. After analyzing the techniques found in the composition of sunburst by Andrew York, the techniques are delivered: 1) There are 2 kinds of slur in the composition of the sunburst, namely: Ascending or Hammer-on and Descending or Pull-off, 2) Barre used in the composition of the sunburst is half barre, 3) Harmonic used in the composition of the sunburst is Natural harmonic and is usually used as a transition transition next sentence. 4) Glissando in the composition of the sunburst is used to facilitate the guitar player when pressing some notes that are considered difficult to play on the left finger, 5) In the composition of the sunburst, from the beginning to the end using the tirando excerpt to play chords, arpeggios, and melodies.
\end{abstract}

Keywords: Playing technique, Classical Guitar, Sunburst, Andrew York

Abstrak: Salah satu komponis pada abad ke 19 adalah Andrew York, lahir pada tahun 1958 di Atlanta dan
dibesarkan di Virginia dan kecintaan terhadap musik ditanamkan pada usia dini. Dari sekian banyak komposisi
yang dibuat Andrew York, sunburst adalah salah satu komposisi yang sangat populer dikalangan masyarakat.
Sunburst sendiri ditulis pada tahun 1986 dan dipublikasikan pada tahun 1998. Penelitian ini bertujuan untuk; 1)
Mendeskripsikan teknik permainan gitar dalam komposisi sunburst karya Andrew York; 2) Mendeskripsikan
faktor-faktor pendukung teknik-teknik gitar klasik dalam memainkan komposisi sunburst Andrew York.
Penelitian difokuskan pada teknik permainan gitar klasik yang terdapat dalam sunburst karya Andrew York.
Penelitian ini merupakan penelitian deskriptif kualitatif. Pengumpulan data dilakukan dengan cara observasi
partisipatif, dokumentasi, dan refrensi. Subjek penelitian dalam penelitian ini adalah partitur sunburst karya
Andrew York, sedangkan objek penelitiannya adalah teknik permainan gitar dalam komposisi sunburst karya
Andrew York. Teknik analisis data dilakukan secara kualitatif yang terdiri atas data reduction (reduksi data),
data display (penyajian data), verification (kesimpulan). Validasi data diperoleh dengan triangulasi data dan
triangulasi pengamat. Hasil penelitian menunjukan bahwa 1) Teknik permainan gitar yang digunakan dalam
sunburst karya Andrew York meliputi; Slur, Barre, Harmonic, Glissando, dan Petikan Tirando, 2) Faktor kendala
yang perlu diperhatikan dalam memainkan sunburst karya Andrew York berkaitan dengan teknik-teknik
permainan gitar klasik yaitu; speed, Power, kesehatan dan ketahanan fisik. Setelah menganalisis teknik-teknik
yang terdapat pada komposisi sunburst karya Andrew York, teknik-teknik tersebut diantarannya: 1) Terdapat 2 
macam slur pada komposisi sunburst, yaitu: Ascending atau Hammer-on dan Descending atau Pull-off, 2) Barre yang digunakan pada komposisi sunburst adalah half barre, 3) Harmonic yang digunakan pada komposisi sunburst adalah Natural harmonic dan biasanya digunakan sebagai transisi perpindahan kalimat selanjutnya. 4) Glissando di komposisi sunburst digunakan sebagai mempermudah pemain gitar saat menekan beberapa nada yang dianggap sulit dimainkan pada jari kiri, 5) Dalam komposisi sunburst, dari birama awal sampai akhir menggunakan petikan tirando untuk memainkan akor, arpeggio, dan melodi

Kata Kunci: Teknik permainan, Gitar klasik, Sunburst, Andrew York

\section{PENDAHULUAN}

Musik tidak lepas dari alat atau bisa dibilang instrumen musik yang memang dapat memproduksi nada. Salah satunya alat atau instrumen tersebut adalah gitar, gitar merupakan instrumen musik yang populer dan umum dijumpai di dunia. Hal ini ditunjukan dengan penikmat instrumen gitar mulai dari kalangan atas hingga kalangan bawah. Gitar mempunyai banyak bentuk, mulai dari gitar klasik, gitar elektrik, gitar bass, gitar akustik elektrik dan lain-lain.

Gitar klasik merupakan salah satu instrumen yang dapat menghasilkan bunyi dengan indah bagi penikmatnya. Menurut Wicaksono (2004:ii), "Untuk pemain gitar tunggal (klasik) yang baik tidak hanya memiliki keterampilan saja, namun juga diperlukan teknik permainan yang baik pula sehingga dalam memainkan sebuah musik akan lebih sempurna". Untuk bermain gitar klasik diperlukan teknik yang benar sehingga karya yang diemainkan benar-benar sempurna.

Akar perkembangan gitar dapat ditelusuri hingga 3000 tahun kebelakang. Pada abad ke-12, Pejuang Salib kembali dari timur ke Eropa, mereka membawa versi awal dari gambus dan vihuela. Dari instrumen ini, awal dari percobaan yang membawa ke arah 'modern' yaitu gitar klasik. 1850-1892 Antonio de Torres mengembangkan gitar dengan memperbesar lubang resonansi hingga berbentuk seperti yang kita kenal saat ini, dan dia juga dikenal sebagai father of the guitar, (Christopher and J. Marshall 1998 : 98). Kemudian gitar mulai menarik perhatian berbagai musisi, sehingga karya bagi gitar bermunculan dan bertambah banyak. Pada tahun 1916 Andres Segovia membuat konser di Ateneo, sebuah aula konser terpenting yang ada di Madrid. Sebelum adanya konser ini, gitar dianggap tidak mampu menghasilkan suara yang sebegitu megahnya. Andres Segovia adalah seorang gitaris klasik yang dijuluki "bapak gitar klasik modern" karena ia mengangkat citra gitar klasik menjadi alat musik konser terhormat yang sejajar dengan piano dan biola. Andres Segovia lahir 21 Februari 1893 dan tutup usia pada 3 Juni 1987 pada umur 94 tahun.

Jubing Kristianto dalam bukunya "Gitarpedia" (2013 : 34), Memasuki abad ke-19, Gitar memasuki kembali gerbang kejayaannya. Pada masa ini lahir para virtuoso dan komposer luar biasa seperti Sor, Giuliani, Aguado, Carcasi, Carulli, Coste, dan banyak lagi. Karya-karya mereka bahkan hingga kini masih menjadi favorit para gitaris modern. Repertoar gitar bertumbuh pesat dengan makin berlimpahnya gitaris dan komposer yang tak henti memopulerkan gitar. Salah satunya Francesco Tarrega (1852-1909), Tarrega adalah perintis permainan gitar klasik menjadi sebuah ilmu dan seni tersendiri. Posisi duduk bermain gitar klasik yang dikenal sekarang ini digagas oleh Tarrega.

Salah satu komponis yang berada pada abad ke 19 adalah Andrew York, lahir pada tahun 1958 di Atlanta, Georgia dan dibesarkan di Virginia. Kecintaannya terhadap musik ditanamkan pada usia dini, ayah York adalah seorang gitaris dan ibunya seorang penyanyi profesional. Dia belajar di Spanyol, di mana dia bertemu gitaris klasik John Williams. Karyanya melewati batas-batas gaya yang tidak biasa, selain kontribusinya terhadap musik klasik, dia juga memiliki latar belakang yang luas sebagai gitaris jazz, belajar dengan lagenda jazz Joe Diorio dan Lenny Breau. Sebagai komponis klasik, York menerima gelar dari Universitas James Madison di Virginia dan University of Southern California. Pada tahun 1989, York merilis album solo debutnya, Perfect Sky (Timeless, 1989). Dia adalah anggota Kuartet 
Gitar Los Angeles hingga 2006. Andrew York adalah satu-satunya alumni dalam sejarah USC yang telah menerima Distinguished Alumni Award dua kali, pada tahun 1997 sebagai anggota Kuartet Gitar Los Angeles dan sekali lagi pada tahun 2003 untuk karir musik solonya.

York memiliki lebih dari 50 karya yang diterbitkan untuk gitar: solo, duo, trio, quartet, dan ensemble. Dia telah merekam atau tampil sebagai solois di lebih dari sepuluh album, dan telah menerbitkan karya tiga volume tentang jazz gitar klasik. York juga pernah bermain di sepuluh rekaman bersama Los Angles Guitar Quartet, termasuk Guitar Heroes pemenang Grammy Award pada tahun 2004. Album solonya meliputi: Perfect Sky (1986), Dénouement (1994), Into Dark (1997), California Breeze (2006), Hauser Sessions (2007), Yamour (2012), Home (2018) dan The Equations of Beauty (2018).

Diantara sekian banyak karya yang diciptakan Andew York, Sunburst termasuk karya klasik modern yang populer di kalangan masyarakat. Sunburst ditulis pada tahun 1986 dan dipublikasikan pada tahun 1998. Pada karya ini ada beberapa teknik yang memang dilakukan secara berulang, untuk dapat menguasai karya ini, ada beberapa teknik dasar yang harus dikuasai, yaitu glissando, slur, harmonic, dan barre.

Pemain gitar tidak hanya harus menguasai teknik, tetapi juga harus menjaga emosi, kestabilan dinamika, dan penjarian tangan kiri untuk membawakan karya ini. Sehingga karya ini pun menjadi salah satu karya dengan tingkat kesulitan yang diatas rata-rata (advance). Hal ini terbukti dengan penguasaan teknik dengan tingkat kesulitan masing-masing dan teknik penjarian tangan.

\section{METODE}

Penelitian ini menggunakan pedekatan penelitian kualitatif deskriptif karena penelitian ini merupakan objek yang tidak perlu menggunakan pengukuran dan proses statistik. Penelitian ini bertujuan untuk mendeskripsikan teknik-teknik apa saja yang digunakan dan faktor kendala saat memainkan komposisi sunburst karya Andrew York. Data yang dianalisis adalah partitur komposisi sunburst karya Andrew York.
Data utama dalam penelitian ini adalah teks musik dari sunburst karya Andrew York. Ditambah dengan beberapa data pendukung eksternal berupa video pertunjukan dari Andrew York saat memainkan komposisi sunburst, bukubuku, artikel dan wawancara dengan narasumber untuk kepetingan analisis data validasi data.

Teknik pengambilan data dari penelitian ini yaitu dengan metode observasi, wawancara, dan dokumentasi. Observasi dilakukan dengan pengamatan langsung terhadap objek penelitian untuk mendapat data mengenai teknik-teknik dan faktor kendala saat memainkan komposisi dari sunburst karya Andrew York. Wawancara ditujukan kepada pihak yang dianggap ahli dan pernah memainkan komposisi sunburst. Peneliti sendiri menunjuk Kanzul Fikri M.Pd sebagai ahli sekaligus informan. Dokumentasi disini berupa partitur dan video dari komposisi sunburst karya Andrew York.

Dalam melakukan analisis data, peneliti menggunakan tiga komponen yaitu reduksi data (data reduction), penyajian data (data display), dan Verifikasi atau penyimpulan data. Data penelitian yang diperoleh melalui teknik pengumpulan data memiliki bentuk yang beraneka ragam. Bisa berbentuk partitur, video, dan hasil wawancara. Penelitian perlu meyortir data-data yang dianggap pokok sehingga dapat lebih mudah dalam melakukan penelitian. Sesuai dengan rumusan masalah penelitian pokok berupa partitur beserta video-video rekaman dari Andrew York saat memainkan komposisi sunburst.

Setelah melakukan reduksi data, langkah selanjutnya yang dilakukan peneliti adalah menyajikannya. Dengan menyajikan data, maka memudahkan untuk memahami apa yang terejadi, merencanakan kerja selanjutnya berdasarkan apa yang telah didapat. Data yang sudah direduksi disajikan kemudian dilakukan pengkajian. Peneliti menggabungkan informasi dari data yang direduksi dan proses tersebut memuat seluruh data yang berupa deskripsi analisis teknik dan faktor kendala saat memainkan permainan gitar sunburst pada komposisi gitar sunburst karya Andrew York. 
Langkah selanjutya yang dilakukan penelitian setelah data tersaji secara sistematis dan terperinci adalah menarik kesimpulan data dan verifikasi data tersebut. Peneliti mendeskripsikan hasil analisis agar mudah dipahami untuk kemudian disimpulkan. Kesimpulan peneliti yang diperoleh tadi kemudian dikaji dengan menggunakan teori yang ada. Proses yang dilakukan peneliti adalah menganalisis teknik permianan gitar pada komposisi sunburst karya Andrew York dengan teori teknik permainan gitar klasik.

\section{HASIL DAN PEMBAHASAN}

Sunburst merupakan salah satu komposisi gitar yang diciptakan oleh Andrew York. Sunburst adalah komposisi dibuat untuk solo gitar yang memiliki tuning Double Drop D, memiliki 3 sukat yaitu 4/4, 3/4, 2/4 dan memiliki 2 tempo yaitu $155 \mathrm{bpm}$ dan $140 \mathrm{bpm}$.

Secara keseluruhan Sunburst ini memiliki 64 birama yang terdiri dari 3 bagian A-B-C-coda. Bagian pertama (A) memiliki 17 birama dengan tempo $155 \mathrm{bpm}$, dibagian ini terdapat beberapa teknik yaitu glissando, barre, dan harmonic dengan teknik petikan tirando. Bagian kedua (B) memiliki 19 birama dan terjadi perubahan tempo dari 155 bpm ke 140 bpm pada birama 30 dan dibagian ini terdapat beberapa teknik yaitu barre dan slur dengan teknik petikan tirando. Bagian ketiga (C) memiliki 27 birama dan terjadi dua kali perubahan sukat, awal perubahan sukat pada birama 48 dan yang kedua pada birama 63 dan dibagian ini terdapat beberapa teknik slur, barre, glissando, dan harmonic dengan teknik petikan tirando.

Teknik slur didalam komposisi sunburst ini ditemukan dua macam teknik slur, yaitu: upward slur dan downward slur.

Salah satu contoh upward slur bisa ditemukan pada birama ke-64.

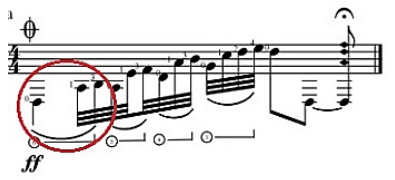

Notasi 1. Upward slur (Sunburst, Andrew York)
Pada birama tersebut teknik slur yang digunakan yaitu single slur karena menggunakan satu jari dan pada satu birama tersebut menggunakan teknik upward slur. Nada yang dimainkan menggunakan jari tangan kanan yaitu nada (D) naik menuju nada (A) dan naik lagi menuju nada (B) dengan satu petikan

Berikut adalah cara memainkannya : Nada yang dimainkan adalah nada (D). Untuk penjarian nada (D) disini menggunakan open string dengan satu petikan bernilai $1 / 4$ ketuk. Kemudian dilanjut dengan menekan nada (A). Untuk penjarian nada (A) penekanan nada menggunakan jari telunjuk bernilai $1 / 8$ ketuk. Dilanjut lagi dengan menekan nada (B). Untuk penjarian nada (B) penekanan nada menggunakan jari manis bernilai $1 / 8$ ketuk secara bergantian tanpa petikan setelah petikan pertama. Petikan menggunakan petikan tiando.

Untuk downward slur, salah satu contohnya bisa ditemukan pada birama ke-58.

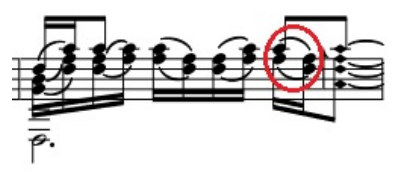

Notasi 2. downward slur (Sunburst, Andrew York)

Pada birama tersebut, dimainkan dengan double slur yaitu menggunakan dua jari secara bersamaan. Nada yang dimainkan menggunakan jari tangan kanan yaitu dari not (F\# dan A) lalu ditekan ke nada yang lebih rendah (D dan F\#) menggunkan jari tangan kiri dengan satu petikan. Karena nada yang dimainkan itu turun, maka menggunakan teknik downward slur atau pull-off.

Berikut adalah cara memainkannya :

Nada yang dimainkan adalah nada (F\# dan A). Untuk penjarian nada $(\mathrm{F} \#)$ penekanan nada menggunakan jari telunjuk dan untuk nada (A) penekanan nada menggunakan jari manis dengan satu petikan bernilai $1 / 4$ ketuk. Kemudian dilanjut dengan menekan nada (D dan F\#). Untuk penjarian nada (D) penekanan nada menggunakan jari telunjuk dan untuk nada (F\#) penekanan nada menggunakan jari yang sama secara bersamaan tanpa petikan setelah petikan pertama. Petikan menggunakan petikan tirando. 
Untuk teknik barre, barre yang digunakan dalam komposisi sunburst menggunkan teknik half barre. Salah satu contoh half barre bisa ditemukan pada birama ke-18.

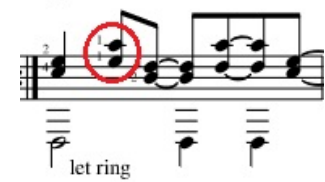

Notasi 3. Half barre

(Sunburst, Andrew York)

Pada bar ke-18 ini adalah tipe teknik half barre, jadi penekanan pada senar tidak pada semua senar. Pada notasi dalam 1 birama di atas terdapat not-not yang dimainkan meggunakan teknik barre, not-not tersebut adalah (E) dan (A) ditekan bersamaan dengan satu jari kiri telunjuk dan dibunyikan secara bersamaan.

Berikut adalah cara memainkannya :

Nada yang dimainkan adalah nada (E dan A). Untuk penjarian menggunakan satu jari kiri pada jari telunjuk dengan satu petikan menggunakan petikan tirando.

Untuk teknik harmonic, harmonic yang digunakan pada komposisi sunburst adalah natural harmonic. Salah satu contoh natural harmonic bisa ditemukan pada birama ke-13.

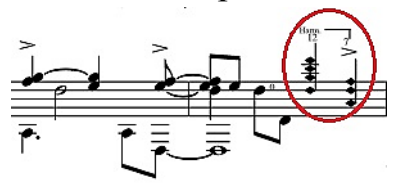

Notasi 4 Natural harmonic

(Sunburst, Andrew York)

Pada birama tersebut, teknik yang digunakan adalah natural haromonic, jadi not tersebut dimainkan dengan teknik harmonic. Pada notasi dalam contoh gambar di atas terdapat not-not yang dimainkan meggunakan teknik harmonic, not-not tersebut adalah (D), (G), (B), dan (D) disentuh bersamaan pada posisi/fret 12 dengan satu jari kiri (barre) dan dibunyikan secara bersamaan.

Berikut adalah cara memainkannya :

Nada yang dimainkan adalah nada (D, G, B, dan D) menggunakan satu jari kiri pada jari telunjuk dengan menyentuh fret ke-12 dan dimainkan pada satu petikan menggunakan petikan tirando.
Untuk teknik glissando, salah satu contoh teknik glissando bisa ditemukan pada birama ke1.

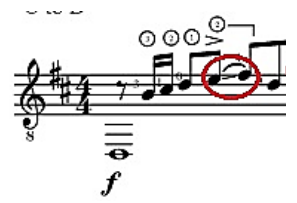

Notasi 5. Glissando

(Sunburst, Andrew York)

Pada birama tersebut, terdapat not yang dimainkan meggunakan teknik glissando, not yang dimainkan adalah nada (E) dengan jari manis, setelah itu jari manis yang menekan nada (E) tadi, di slide atau diluncurkan ke nada (F\#) dengan satu petikan.

Dari semua teknik yang sudah disebutkan sebelumnya, teknik petikan yang digunakan pada komposisi sunburst adalah teknik petikan tirando. Selain untuk memainkan teknik yang ada pada komposisi sunburst, teknik petikan tirando juga digunakan dalam memainkan akor, arpeggio, dan melodi yang berada pada komposisi sunburst karya Andrew York.

Di dalam komposisi sunburst karya Andrew York banyak sekali bagian-bagian yang berupa akor. Akor-akor tersebut dimainkan dengan petikan tirando. Salah satu contoh akor yang dimainkan dengan teknik petikan tirando bisa ditemukan pada birama ke-18.

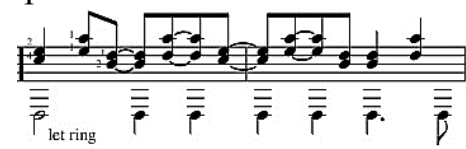

Notasi 6. Akor menggunakan teknik petikan tirando

(Sunburst, Andrew York)

Selain akor, terdapat beberapa bagian yang dimainkan dengan arpeggio. Salah satu contoh arpeggio yang dimainkan dengan teknik petikan tirando bisa ditemukan pada birama ke-30.

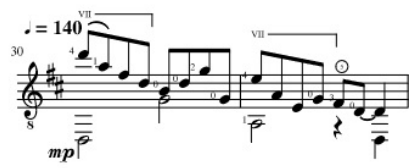

Notasi 7. Arpeggio menggunakan teknik petikan tirando

(Sunburst, Andrew York)

Melodi-melodi pada komposisi sunburst dimainkan dengan petikan tirando. Dengan petikan tirando kebanyakan melodi tersebut lebih 
ringan dan nyaman untuk dimainkan. Salah satu contoh melodi yang dimainkan dengan teknik petikan tirando bisa ditemukan pada birama ke5.

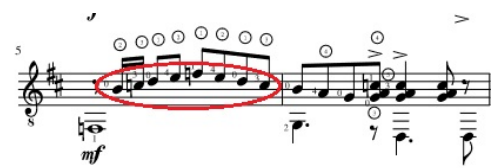

Notasi 8. Melodi menggunakan teknik petikan tirando

(Sunburst, Andrew York)

Sunburst merupakan komposisi gitar yang mempunyai berbagai jenis teknik permainan di dalamnya sehingga untuk membawakan karya ini dengan baik maka seorang pemain dituntut harus mengetahui teknik apa saja yang digunakan dalam komposisi ini. Faktor kendala saat memainkan komposisi sunburst ini adalah: speed, power, dan kesehatan dan ketahan fisik.

Beberapa bagian dalam komposisi ini menggunakan not $1 / 16$ dan sebagian menggunakan not $1 / 32$ sehingga dituntut untuk memainkan dengan cepat juga terdapat dalam beberapa bagian dalam komposisi ini.

Bisa dilihat pada birama ke-38, ini salah satu bagian pada komposisi sunburst yang memerlukan kecepatan dalam memainkanya.

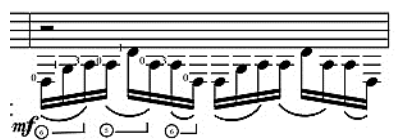

Notasi 9. Speed

(Sunburst, Andrew York)

Pada bagian ini memerlukan pergerakan yang cepat untuk dimainkan dengan not 1/16 dengan penggunaan teknik slur, semata-mata tidak hanya kecepatan yang menjadi masalah, namun karena posisinya yang sulit untuk dimainkan dengan cepat dan jelas.

Selain speed, power perlu diperhatikan secara detail dalam memainkan komposisi sunburst. Dalam komposisi sunburst, terdapat beberapa bagian yang sulit untuk dimainkan dengan power yang bagus.

Bisa dilihat pada birama ke-48-49, ini salah satu bagian pada komposisi sunburst yang memerlukan power yang bagus.

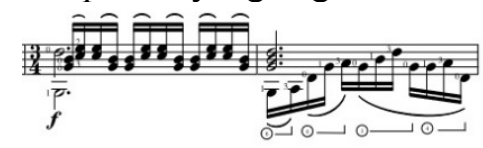

Notasi 10. Power (Sunburst, Andrew York)
Pada bagian ini perlu dimainkan perlu dimainkan dengan dinamik $f$ (forte). Namun tetap memperhatikan kemampuan volume pada alat musik gitar dan tidak melebihi kemampuan dari alat musik itu sendiri. Menggunakan warna suara (tone colour) memungkinkan kita untuk memberikan kekuatan yang diperlukan untuk memainkan akor dan melodi.

Faktor kendala lainnya adalah kesehatan dan ketahanan fisik. Karena Sunburst merupakan sebuah komposisi jumlah yang tidak banyak yaitu 64 birama tetapi memiliki banyak repetisi, dengan tingkat kesulitan yang tinggi (advance). Seorang pemain gitar klasik sebaiknya memiliki ketahanan fisik yang baik dalam bermain, untuk dapat memainkan sunburst dengan baik.

Pemain gitar klasik sebaiknya mengetahui bagaimana posisi duduk yang baik, posisi tangan yang baik, dan posisi tubuh yang baik. Dengan posisi yang baik maka pemain gitar klasik tidak merasakan ketegangan diantara otot-otot tubuh baik otot badan, tangan, maupun jari.

Dengan demikian ketahanan fisik dapat dijaga dan mampu memainkan komposisi sunburst karya Andrew York yang memiliki banyak repetisi dengan tingkat kesulitan tinggi.

\section{PENUTUP}

Sunburst adalah salah satu komposisi karya Andrew York yang memiliki beragam teknik, teknik-teknik tersebut diantarannya: slur, barre, harmonic, glissando, dan teknik petikan tirando.

Di dalam komposisi sunburst Terdapat 2 macam slur, yaitu: Ascending atau Hammer-on dan Descending atau Pull-off. Barre yang digunakan pada komposisi sunburst adalah half barre. Harmonic yang digunakan pada komposisi sunburst adalah Natural harmonic dan biasanya digunakan sebagai transisi perpindahan kalimat selanjutnya. Glissando di komposisi sunburst digunakan sebagai mempermudah pemain gitar saat menekan beberapa nada yang dianggap sulit dimainkan pada jari kiri.

Dalam komposisi sunburst, dari birama awal sampai akhir menggunakan petikan tirando untuk memainkan akor, arpeggio, dan melodi.

Untuk faktor kendala saat memainkan komposisi sunburst ini adalah: speed, power, dan kesehatan dan ketahan fisik. 


\section{DAFTAR PUSTAKA}

Banoe, Pono. (2003). Kamus Musik. Yogyakarta: Kanisus

Chirstoper P. (1972). The Christopher Parkening Guitar Method. U.S.A

Wicaksono, Herwin, Yogo (2004). Praktik individual mayor 1 gitar. Yogyakarta

Kristianto, Jubing. (2005). Gitarpedia. Jakarta: P.T. Gramedia Pustaka Utama

Kristianto, Jubing. (2007). Gitarpedia. Jakarta: P.T. Gramedia Pustaka Utama

Moleong, Lexy. (2007). Metodologi Penelitian Kualitatif. Bandung: Remaja Rosdakarya

Phillip and Chappel. (2009). Classical Guitar for Dumies. USA

Sugiyono. (2006). Metode Penelitian Kuantitatif Kualitatif dan R\&D. Bandung: C.V.

Alfabeta

Sugiyono. (2008). Metode Penelitian Kuantitatif Kualitatif dan R\&D. Bandung: C.V.

Alfabeta

Sugiyono. (2012). Metode Penelitian Kuantitatif Kualitatif dan $R \& D$. Bandung: C.V.

Alfabeta

Sumerfield, A. B. 1982. Body Image : A Selective Review of Existing Measurement Techniques.

Pustaka maya

https://manoa.hawaii.edu/music/event/andrewyork-guitar/ 